\title{
VELOZ MAGGIOLO \\ Y LA NARRATIVA DE DICTADOR/DICTADURA: \\ PERSPECTIVAS DOMINICANAS E INNOVACIONES
}

POR

SHARON KEEFE UGALDE

Southwest Texas State University

\section{CARACTERÍSTICAS DE LA NARRATIVA DICTADOR/DICTADURA}

El eco de apellidos como Trujillo, Batista, Estrada Cabrera, Ubico, Somoza, Pérez Jiménez, Rosas y Pinochet nos recuerda la presencia de regímenes dictatoriales a lo largo de la historia de América Latina. El deseo de comprender este fenómeno se manifiesta en el desarrollo de un subgénero literario conocido como «novela del dictador», cuya visión, al contrario de otras áreas del saber humano, es afectiva y sintética. Pero el nombre «novela de dictador» tiene dos limitaciones serias. Una de ellas es que no permite la inclusión de cuentos ni de otros textos que se acercan a la historia o al ensayo. La otra falla reside en que no todas las obras tratan sobre el dictador, hay varias que hacen referencia solamente a los efectos de la dictadura. Preferimos usar el término «narrativa de dictador/dictadura», en el cual incluimos sólo los textos cuyo enfoque principal es un dictador o los efectos de la dictadura ${ }^{1}$.

Se puede dividir la evolución de este subgénero en tres períodos. La etapa inicial incluye los prectursores del siglo XIX y los escritores de la primera mitad del siglo. Durante esta etapa, el propósito principal de las obras es la condenación de la tiranía, con un énfasis en los sucesos históricos recientes ${ }^{2}$. La publicación de Tirano Banderas (1926) anticipa el

${ }^{1}$ Carlos Pacheco, «Algunas consideraciones metodológicas sobre la narrativa de la dictadura: el caso de La sombra del caudillo, de Martín Luis Guzmán», trabajo leído en el XX Congreso del Instituto Internacional de Literatura Iberoamericana, Austin, TX, 1981, describe el subgénero con el término «narrativa» en vez de «novela» por las mismas razones que presentamos.

${ }^{2}$ Los más destacados precursores son Domingo Faustino Sarmiento, Civilización y barbarie: Vida de Juan Facundo Quiroga (1845); Esteban Echevarría, El matadero 
segundo período, en el cual se incluye también como obra seminal El Señor Presidente (1946). Durante esta etapa, los autores siguen expresando una condenación de los abusos del poder, pero existe una nueva preocupación con el valor estético del texto. La aparición de El recurso del método, Yo el Supremo y El otoño del patriarca, en los años 1974-1975, representa un punto clave en la evolución del subgénero, al introducir al dictador como protagonista, visto desde «adentro», narrando sus experiencias en primera persona.

La coincidencia del interés de prestigiosos escritores del boom en la narrativa de dictador/dictadura, junto con la innovadora perspectiva de indagar la psicología del tirano, atrajo la atención de los críticos, quienes analizaron más a fondo esta narrativa, dividiéndola en dos categorías: «de dictador» y «de dictadura» (también 1lamada «con dictador») ${ }^{3}$. La primera incluye obras que estudian la personalidad tiránica del protagonista, dentro de un espacio mitificado e integrador. La segunda contiene textos con una orientación sociológica y política e intenta transponer a la ficción un momento histórico determinado. En su evaluación del subgénero, los críticos tienden a colocar a la novela «de dictadura» en una posición de inferioridad con respecto a la «de dictador», por su énfasis en la función referencial del lenguaje y por incluir en algunas obras personajes superficiales, y porque otras son de tipo panfletista.

El fallo a priori en contra de la narrativa de dictadura no tiene fundamento. La ausencia de un dictador-protagonista no siempre tiene por qué acabar en una caracterización superficial, como demuestra, por ejemplo, El Señor Presidente, que ofrece una profunda visión psicológica de la colectividad que vive bajo una dictadura, y Los ángeles de hueso (1967), que logra lo mismo desde una perspectiva individual. Además, el peligro de desbordarse en el panfletismo no existe solamente en las novelas «de dictadura». Obras como El General Otte (1966), de Alvaro Contreras Vélez, y El pueblo soy yo (1976), de Pedro Jorge Vera, por ejemplo, tienen un dictador como figura principal, pero les falta el esteticismo deseado. Por el contrario, hay novelas «de dictadura», incluso obras que abarcan sucesos históricos cercanos a la fecha de composición, que se mantienen dentro de los límites del arte literario, asignando un papel

(¿1883?); José Mármol, Amalia (1851-1855), y Mercedes Cabello de Carbonera, El conspirador (1892).

${ }^{3}$ Me refiero especialmente a dos trabajos: Bernardo Subercaseaux, «Tirano Banderas en la narrativa hispanoamericana (La novela del dictador, 1926-1976)», en Hispamérica, año V, núm. 14 (agosto 1976), y Jorge Castellanos y Miguel A. Martínez, «El dictador hispanoamericano como personaje literario», en Latin American Research Review, vol. XVI, núm. 2 (1981). 
de privilegio a la función poética del lenguaje, como, por ejemplo, Hombres a caballo (1967), de David Viñas; Conversaciones en la catedral (1969), de Mario Vargas Llosa; El gran solitario del palacio (1971), de René Avilés Fabila, y La Linares (1977), de Iván Equez.

La dicotomización del subgénero no sólo implica una evaluación errada, sino que también destruye la posibilidad de comprender la relación que existe entre dictador y pueblo. Tanto José Martí como Angel Rama subrayan la interrelación íntima entre dictador y sociedad: «El dictador no era una aberración, sino el producto de una relación profunda con la sociedad latinoamericana a la que expresaba cabalmente, en especial respecto a las vastas masas incultas que constituían la inmensa mayoría» ${ }^{4}$. Manuel Rueda describe la misma relación en términos de una interrelación triangular: «El dictador sería entonces sólo un lado de ese triángulo, que completan pueblo e historia, en tensiones y distensiones sucesivas» ${ }^{5}$. Concebir la narrativa de dictador/dictadura bajo una perspectiva conjuntiva facilita entender que este subgénero, en su conjunto, es un vehículo extraordinario para la reivindicación de la historia y la búsqueda de una verdad libre de distorsionadas versiones oficiales ${ }^{6}$. Va más allá de la expresión afectiva del terror, de la soledad o de la esperanza de la liberación, y es capaz de crear una estructura dialógica entre el poder y el no-poder, que incorpora múltiples discursos. La historia, la política, la sociología, el folklore, la filosofía y la lingüística se entrelazan, llevando al lector hacia una visión sintética de la realidad de la región. Esperamos

${ }^{4}$ Angel Rama, Los dictadores latinoamericanos (México: Fondo de Cultura Económica, 1976), p. 6. Véase también José Martí, «Nuestra América», en José Martí, Nuestra América (Sucre, Venezuela: Biblioteca Ayacucho, 1977). Gonzalo DíazMigoyo, «Tirano Banderas y la novela del dictador», en Diálogos, vol. 19, núm. 6 (14) (noviembre-diciembre 1983), pp. 16-25, elabora el concepto integrador del subgénero. Véase también Rudolf Grossmann, Historia y problemas de la literatura latinoamericana (Madrid: Revista de Occidente, 1972), pp. 42-51, para un estudio del concepto de síntesis como característica de la literatura latinoamericana. Aunque Grossmann pone más énfasis en lo socio-cultural, el proceso sintético descrito es el mismo que se manifiesta a nivel socio-político en la narrativa de dictador/dictadura.

${ }^{5}$ Manuel Rueda, "Presencia del dictador en la narrativa dominicana», en $\mathrm{El} \mathrm{dic}$ tador en la novela latinoamericana (Ponencias de un seminario realizado los días 2 , 3, 4 de octubre de 1980) (Santo Domingo: Voluntariado de las Casas Reales, s. f.), p. 114.

"Mario Vargas Llosa, «Social Comment and the Latin American Writer», en World Literature Today, vol. 52, núm. 1 (1978), pp. 6-8, subraya el papel «libertador»r de la literatura latinoamericana: "What was for political reasons, repressed or distorted in the press and in the schools and universities, all the evils that were buried by the military and economic elite which ruled the countries, the evils which were never mentioned... found a vehicle of expression in literature.» 
que esta introducción sirva al doble propósito de destacar la necesidad de mantener la unidad del concepto dictador/dictadura y de disolver los prejuicios que puedan existir en contra de la producción dominicana, por su escasez, hasta muy recientemente, de narrativas con un dictador-protagonista y un espacio imaginario.

\section{LA NARRATIVA DE DICTADOR/DICTADURA EN LA República Dominicana}

Francisco García Godoy (Guanuma, 1914) y Tulio Manuel Cestero (La sangre: una vida bajo la tiranía, 1915) son dos precursores, seguidos, un poco más tarde, por Andrés Requena, quien publicó, en la década de los cuarenta, dos novelas que caben dentro del subgénero, pero la mayoyoría de los textos del subgénero en la República Dominicana son de los últimos veinticinco años ${ }^{7}$. En su compilación de la narrativa dominicana de dictador/dictadura, Manuel Rueda incluye un total de once novelas y once cuentos, y entre ellos sólo una novela, Las tinieblas del dictador (1978), de Haffe Serulle, y dos cuentos, tienen al dictador como protagonista ${ }^{8}$. A estos tres habría que añadir La biografía difusa de Sombra Castañeda (1980), que salió después de que Rueda hubiese preparado su estudio ${ }^{9}$.

El por qué los escritores de la República Dominicana han optado por dar énfasis al efecto de la dictadura en el pueblo, dejando al dictador como una figura de fondo, es campo de la especulación. La explicación más lógica es que hay mucha sangre que no se ha secado todavía. Con las excepciones de Guanuma y el cuento «Laudín», de Georgilio Mella Chavier, que se basan en la vida de Santana; La sangre y Los despojos del Cóndor (Pedro Peix, 1980), que retrata a Lilís, y Las tinieblas del dictador, que tiene un dictador compuesto, Trujillo sirve como inspiración para las demás narrativas. Es probable que los escritores hayan sentido una necesidad urgente de expresar la versión oprimida y callada de la historia inmediata, la realidad vivida, antes de destilarla, mitificando al dictador o dándole una voz principal. También es posible que exista cier-

${ }^{7}$ Andrés Requena, Camino de fuego (Santiago, Chile: Ercilla, 1941); Cementerio sin cruces (México, 1949).

"Los dos cuentos con un dictador-protagonista son: "Laudín», de Georgilio Mella Chavier, y «El dictador», de León David.

- Marcio Veloz Maggiolo, La biografía difusa de Sombra Castañeda (Caracas: Monte Avila, 1980). Otras referencias a esta obra se anotarán en el texto con BD y el número de la página. 
to miedo de penetrar y comprender la psicología del dictador por temor a perdonarlo ${ }^{10}$.

Marcio Veloz Maggiolo figura entre los escritores dominicanos que más se han ocupado del subgénero. De su obra narrativa, cuatro novelas, El prófugo (1963), Los ángeles de hueso (1967), De abril en adelante (1976) y La biografía difusa de Sombra Castañeda (1980), y dos cuentos, «La vida no tiene nombre» (1963) y «El coronel Buenrostro» (1982), son de dictador/dictadura ${ }^{11}$. La mayoría de estas obras revela la perspectiva típica dominicana de presentar los efectos de la dictadura y de reflejar un pasado histórico reciente. En este estudio nos limitaremos a las cuatro novelas cuya evolución revela la variedad de patrones estructurales y estilísticos que caben dentro de los parámetros del subgénero. Veloz, como los otros escritores de esta narrativa, busca la expresión indirecta y el silencio para mantener el equilibrio entre el deleite del esteticismo y la lección en contra de la tiranía. Necesita encontrar patrones que involucren al lector en la experiencia del texto, porque el placer y la significación de la obra dependen de su participación, como subraya Wolfgang Iser ${ }^{12}$. En las novelas de Veloz, la ironía, que es un patrón dominante en el subgénero, sólo juega un papel marginal, sea en forma de destellos trágicos de dilemas que niegan solución, o en forma de humor satírico ${ }^{13}$. El autor dominicano emplea, sobre todo, el espacio cerrado, los leitmotivs, las técnicas del nouveau roman, la poliglosia y la alegoría. Dos de sus novelas, Los ángeles y La biografia, representan importantes innovaciones en la narrativa de dictador/dictadura.

${ }^{10}$ García Márquez confiesa haber enfrentado este dilema al escribir El otoño del patriarca: «Ahora, el gran problema de conciencia que tengo yo es el temor de que toda esta meditación absuelva al dictador, en el sentido de que aparezca como víctima de un aparato y de un conjunto de circunstancias, cosa que no creo que sea históricamente cierta.» Ernesto González Bermejo, «García Márquez: Ahora doscientos años de soledad», en Gabriel García Márquez, ed. de Peter G. Earle (Madrid: Taurus, 1981), p. 257.

${ }^{11}$ Otras obras de Marcio Veloz Maggiolo son: novelas: El buen ladrón (1960), Judas (1962); novelas cortas: Seis relatos (1963); cuentos: De donde vino la gente (1978), La fértil agonía del amor (1982); obra teatral: Creonte (1963); poesía: Intus (1962), Trinsparencias: poemas (1971).

${ }^{12}$ Wolfgang Iser, The Act of Reading. A Theory of Aesthetic Response (Baltimore and London: The John Hopkins University Press, 1978).

${ }^{13}$ Entre los patrones dominantes del subgénero figuran la ironía, por mucho el más frecuente y el más logrado; el empleo del arquetipo, y desde 1970, las técnicas del nouveau roman y la mitificación. Véase Sharon Keefe Ugalde, «La ironía y los dictadores en Hispanoamérica», en Plural, vol. XIII, núm. 156 (septiembre 1984), pp. 19-24. Arturo Uslar Pietri, Oficio de difuntos (Barcelona: Seix Barral, 1976), sirve como ejemplo del empleo del arquetipo y Otoño del Patriarca y Yo el Supremo ofrecen excelentes ejemplos de patrones míticos. 
«EL PRÓFUGO»

El prófugo es el primer intento del autor de enfrentarse con la dictadura de Trujillo en una novela ${ }^{14}$. En esta obra corta no hay ningún intento de enmascarar la época histórica. La acción parte del acontecimiento real del asesinato de Trujillo, perpetrado por un grupo de hombres en la carretera Santo Domingo-San Cristóbal. Tampoco hay ambiguiedad con respecto a la condenación del régimen. Al retratarlo sobresalen sus métodos sangrientos, la injusticia social, la supresión oficial de la verdad en los periódicos y por la radio y, paradójicamente, el discurso literario es algo dictatorial. La narración omnisciente en tercera persona y el orden cronológico, con sólo unos breves analepses, no exigen un alto grado de participación ${ }^{15}$. Además, el espacio es fácilmente identificable: la carbonera donde se esconde Alberto y sus alrededores, la casa del guardia Angel Hortón, la iglesia que visita brevemente el prófugo y la calle donde muere.

Por falta de la expresión indirecta, el texto no alcanza a expresar una complejidad sintética, pero sí consigue, hasta cierto punto, una intensidad afectiva, concentrándose en las emociones de repugnancia, miedo, terror y desesperación. La selección de dos «atrapados» como protagonistas, el prófugo Alberto, que acaba de participar en el asesinato de Trujillo y el policía nacional Angel Hortón, que quiere dejar de ser un asesino oficial del régimen, contribuye a expresar el contenido emocional. Producen el mismo efecto la acumulación de paradigmas de animales (moscas, perros, pulgas, fieras, ratones), del color negro (oscuridad, noche, sombras, tizne, cisco, carbonero) y de palabras asociadas con la muerte (inerte, inmóvil, póstumo, agonizaba, enfermiza, golpeo, lacerado, genocida, sangre), y la elaboración de ciertos símbolos, sobre todo el revólver de Alberto, que sugiere que la violencia es un sistema inalterable de la realidad nacional ${ }^{16}$.

${ }^{14}$ Marcio Veloz Maggiolo, El prófugo (Santo Domingo: Brigadas Dominicanas, colección «Baluarte», 1962).

${ }^{15}$ Gérard Genette, Narrative Discourse: An Essay in Method (Ithaca: Cornell University Press, 1980), pp. 35-62, describe varios tipos de analepsis, que definen la discordancia entre la ordenación de la historia y la ordenación de la narrativa.

16 Andrés Requena formula la misma conclusión en El cementerio sin cruces, y Ariel Dorfman, Imaginación y violencia en América (Barcelona: Anagrama, 1972), p. 15, la resume de esta forma: «En Hispanoamérica, la violencia no es el segundo polo o término de una dualidad... Es la estructura misma en que me hallo... no entregarse a ella significa morir o perder la dignidad o rechazar el contacto con mis semejantes.» 


\section{«LOS ÁNGELES DE HUESO»}

En Los ángeles de hueso, en mucho mayor grado que en El prófugo, el lector participa en la formulación de la significación del texto, juntando y ordenando las imágenes y las acciones aparentemente incomprensibles que brotan del mundo alucinante de la locura ${ }^{17}$. El narrador-protagonista es un joven estudiante de la época postrujillista que se vuelve loco al ver el cuerpo destrozado de su hermano Juan, un rebelde asesinado por el gobierno. Dentro de la narrativa de dictador/dictadura, Los ángeles representa una innovación importante, porque presenta la fuerza destructiva de la dictadura a través de la penetración psicológica de un individuo que narra su historia en primera persona. La técnica de stream of consciousness permite la entrada al mundo de la locura, donde no existen divisiones entre el pasado y el presente ni entre lo real y lo imaginario. En el trasfondo de la irracionalidad, que a veces da risa -un tiburón pirata, plumas que hablan, el sentarse en el techo-, el lector escucha el eco de una carcajada desesperada. La referencialidad escondida detrás de la locura no se limita a destacar los abusos de Trujillo. La historia de la injusticia es más compleja: existe desde la época de Colón, sus causas son tanto internacionales como nacionales, y se extiende por toda América Latina ${ }^{18}$.

El sistema opresivo dominicano es tan grave que si uno no escoge la violencia - luchar contra el régimen como Juan o suicidarse como Farina-, la única otra vía para un ser sensitivo es la locura. El sentir el sufrimiento de los demás, sin poder remediarlo, se convierte en un destino trágico. La compasión del protagonista es descomunal. De niño sentía hasta las molestias que afligían a la estatua de San Juan que salía en las procesiones: «Nunca dije a Juan (su hermano) que la banda de los bomberos molestaba a San Juan. Nunca quise decírselo» (p. 43). Aun en la locura, él más que nadie, percibe lo que ocurre a su alrededor, desde el

${ }^{17}$ Marcio Veloz Maggiolo, Los ángeles de hueso (Santo Domingo: Arte y Cine, colección «El Puño», 1967). Otras referencias a esta novela se anotarán en el texto con el número de la página.

${ }^{18}$ Las citas y referencias siguientes ejemplifican la visión compleja de la injusticia que ofrece la obra. Con respecto a su larga historia: "(Colón) Amó esta tierra más que muchos aunque no a sus indios, a los cuales les lanzó perros hambrientos en el valle de la Vega Real» (AH, p. 25). Con respecto a la intervención de los Estados Unidos, hay mención de la CIA en las montañas y de ESSO en la barriga de los tiburones. Con respecto a la extensión del problema: «En algún pueblo de México se levanta hoy otro Juan, en algún pueblo de Bolivia, en algún pueblo de Ecuador, en algún poblado de Paraguay» (AH, p. 110). 
baile de los colores de la alfombra hasta los sonidos lejanos de los grillos (p. 96). Según nuestra lectura, Los ángeles tiene un valor metafórico, que expresa el efecto destructivo de la dictadura en la gente que la sufre a diario. La existencia es tan dolorosa que la muerte se transforma en una especie de liberación. Se describe a Farina, comida por los tiburones, como "recién muerta», pero también como «recién viva» (p. 63). Es un mundo al revés, en el que el loco es el sano: «No comprenden que soy un ser más normal que los demás y que por eso parezco anormal. No comprenden nada» (p. 72). La voz desesperada del narrador-protagonista resume esta significación de la manera siguiente: «Mis memorias son una gran carcajada que se inicia en la primera línea y que termina en el colofón. Podrán comenzar esta novela por la mitad, podrán comenzarla por la página final, no importa, lo importante es que alguien diga algo, que refleje el sufrimiento de los demás» (p. 44).

Un espacio cerrado, semejante a la figura del «atrapado», de El prófugo, contribuye a la construcción de la experiencia textual. Un lugar cerrado y sin salida hace pensar en algunas instituciones como la prisión y el hospital mental, cuyas características incluyen el «aislamiento respecto al mundo exterior» y «la ruptura total entre gobernantes y gobernados» ${ }^{19}$. En estas instituciones, igual que en una tiranía, las autoridades oprimen a los subordinados. Sin embargo, un número limitado de pequeñas «fisuras» permiten, aunque sea brevemente, la posibilidad de cambio. En Los ángeles, el hermano de Juan se atreve a romper el espacio cerrado, al reunirse con las fuerzas revolucionarias, pero el protagonista se queda debilitado, encerrado en prisiones concéntricas: su cuarto, la dictadura y la loctra. El valor intertextual -literario y extraliterariodel espacio cerrado enriquece las posibilidades expresivas de la novela ${ }^{20}$.

Desde la perspectiva de los cuerdos, tanto la acción como el espacio son muy limitados. El protagonista vive una vida de tedio, con pocas distracciones: la visita de la madre, de una mujer que dice ser su esposa y del médico, que le inyecta «miel de abejas». Pero la acción imaginaria ofrece horizontes mucho más amplios. Recuerdos recientes - la historia

\footnotetext{
${ }^{19}$ Jacques Donzelot, «Espacio cerrado, trabajo y moralización», en Espacios del poder (Madrid: Piqueta, 1981), p. 27.

${ }^{20}$ El espacio cerrado es frecuente, por ejemplo, en la literatura feminista como símbolo de la falta del poder de la mujer. Véase Sandra M. Gilbert y Susan Gubar, The Madwoman in the Attic. The Woman Writer and The Nineteenth-Century Literary Imagination (New Haven and London: Yale University Press, 1979), pp. 86-91. En el contexto del subgénero, véase Teresa Méndez-Faith, «Dictadura y 'espacios-cerrados' en Hijo de hombre y Yo el Supremo», en Chasqui, vol. XIII, núm. 1 (noviembre 1983), pp. 3-11.
} 
de su hermano- y lejanos - la niñez y su amiga Indiana- se entremezclan con visiones oníricas de figuras y escenas inverosímiles. Varios recursos ayudan a crear la irracionalidad del joven, como, por ejemplo, unas series de imágenes cuyo patrón metonímico no se basa en la lógica, sino en la repetición arbitraria de alguna palabra de la imagen anterior o en la sinestesia. Otro recurso es la presentación de una lógica ilógica, que se asemeja a la manera de pensar de un niño; por ejemplo, en una ocasión el protagonista piensa que si él sueña con monstruos, los ratones, siendo pequeños, deben soñar con monstruitos.

El lector, fácilmente, podría perder el camino hacia la significación del texto entre las múltiples visiones alucinantes - el peligro, opuesto al que se manifiesta en El prófugo- si no fuera por la presencia de unos leitmotivs. Estos paradigmas de imágenes, símbolos y frases recurrentes, con asociaciones estáticas, sirven como signos de unidad textual. Frecuentemente el narrador resume, en un párrafo, varias imágenes previamente elaboradas o abre y cierra un capítulo con la misma imagen (la gaviota en cap. XIII, por ejemplo, o las tumbas y el zumbar de los muertos en cap. IX). Los leitmotivs son numerosos y variados: el relato de una mujer campesina, Farina, que se suicida y es comida por los tiburones; una composición musical contemporánea, Nexus 16; helicópteros con águilas pintadas, hélices que giran, bomberos y fuego, el ruido estridente de tambores y de fuegos artificiales, automóviles oficiales, tarántulas, ratones y la repugnante descripción del cuerpo de Juan.

En rasgos generales, podemos agrupar las connotaciones de los leitmotivs de la forma siguiente: las que expresan el miedo y el odio que nacen de la violencia; otras que indican explotación y regresión, y aquellas que manifiestan la indiferencia frente a los demás. E1 autor sugiere una asociación entre la negatividad de las imágenes y la República Dominicana de los últimos años de Trujillo. La imagen de la gaviota, por ejemplo, introducida como animal avaro y odiado en el primer capítulo, se carga de mayor significación cuando el autor añade una comparación en el capítulo XII: "Una gaviota sucia de grasa: bonita definición para la vida en este país isleño chico y violento, explotado y maltrecho». (p. 110).

El silencio final del texto, la falta de soluciones concretas, también contribuye a evitar el aburrimiento de la diatriba. El autor no ofrece ningún sistema alternativo, ni siquiera un posible fin al sufrimiento. E1 penúltimo capítulo narra un episodio en el cual el protagonista y otros compañeros llegan a una pensión nueva, que luego abandonan después de mucha paciencia, porque es siempre mañana cuando terminarán de arreglar lo prometido. Este relato metafórico pronostica un futuro pesi- 
mista sin cambios: «Cuando me iba preguntó (el hospedero) a uno de mis compañeros que si no nos agradaba el lugar. Caminamos en silencio por las calles polvorientas y comprendimos que el mañana tiene los ojos grises» (p. 125).

\section{«DE ABRIL EN ADELANTE»}

De abril en adelante integra, por primera vez, una visión del dictador con la dictadura. Predomina la perspectiva característica de las novelas anteriores, un enfoque en los efectos de la opresión, con el dictador visto desde lejos como una fuente de órdenes sagradas ${ }^{21}$. Sin embargo, por medio de la creación del personaje del coronel Aguirre, Veloz logra el estudio de una personalidad tiránica ${ }^{22}$. Dentro del terreno que le asigna Trujillo, el coronel representa un poder absoluto. A través de una narración en tercera persona, el lector llega a conocer los actos criminales de Aguirre. También hay vislumbres de la psicología del personaje, sobre todo su sistema de valores. La determinación de mantener el status que el político le trae, sobresale como la motivación subyacente de todas sus acciones. El coronel es capaz de eliminar a cualquiera que amenace su posición. En una ocasión encarcela secretamente, y luego asesina, al capitán Monsanto, cuyo único error fue mostrarle a Aguirre su superioridad durante las luchas en Constanza, en 1959 (p. 247).

La figura de Aguirre, vista desde afuera y desde adentro, hace que De abril sea una novela de dictador, mientras la figura de su hijo Paco, protagonista y narrador de amplias secciones de la novela, proyecta la imagen de alguien que sufre los efectos de la dictadura. Como universitario izquierdista, Paco pierde a compañeros queridos y llega el momento que tiene que exiliarse en Nueva York, donde difícilmente se gana la vida como pintor de brocha gorda. Al regresar a la República, después de la caída de Trujillo, se mete en política, y, desilusionado con el partitido Unión Cívica, acaba luchando en la guerra de abril. Unos años después le despiden de su trabajo en el periódico - que irónicamente sólo tiene porque es el hijo del coronel- por escribir negativamente sobre el papel del capital norteamericano en la época postrujillista. El sufrimiento

${ }^{21}$ Marcio Veloz Maggiolo, De abril en adelante, 2. ${ }^{a}$ ed. (Santo Domingo: Taller, 1984). Otras referencias a esta novela se anotarán en el texto con De abril y el número de la página.

${ }^{22}$ El personaje de Aguirre se transforma en el coronel Buenrostro en el cuento «E1 coronel Buenrostro». Véase Marcio Veloz Maggiolo, La fértil agonía del amor (Santo Domingo: Taller, 1982). 
que causa la represión en la época en que Aguirre lleva a cabo sus órdenes, se transforma luego, para Paco, en un ambiente de letargo que asfixia e inmoviliza, revelando el efecto duradero de la dictadura. Como los protagonistas de El prófugo y de Los ángeles, Paco es un «atrapado», vive en un círculo burgués sin salida: "Abril, el mar, Nueva York, las mujeres, los amigos, el grupo, el ron, constantemente y continuamente lo mismo» (p. 225).

De abril en adelante es un retrato histórico de los jóvenes intelectuales del período que va desde los últimos años del régimen de Trujillo hasta el año $1970^{23}$. Para crear el retrato, Veloz estructura un personaje colectivo, que consiste en un pequeño grupo de escritores y artistas. Los miembros -Paco, Persio, Russo, Ramón, Sanluis, Carlos Julio, Samuelentran y salen en la acción, algunos más frecuentemente que otros, pero lo que sobresale es que todos - menos Russo, que va a la montaña a organizar a los campesinos - han heredado el mismo estado de estancamiento. Ni ganan las revoluciones -muchos participaron en la derrota de la guerra de abril- ni escriben las obras que se proponen. La inhabilidad del narrador de De abril de encontrar una estructura narrativa adecuada refracta los fracasos artísticos del grupo. Para dar énfasis a la situación colectiva, el autor multiplica las terminaciones verbales de la voz narrativa y los referentes de los pronombres. Por ejemplo, un «tú» se vuelve «yo»: «ca-mi-nas (no)... Pero ya ves, de pronto te (me) arrepientes (to)» (p. 211); o se convierte en «nosotros»: «Y en lo impersonal habría que pensar digo (dices, claro) que esto es una justificación tuya (¿nuestra?) y que temes (o ¿tememos?) nuestras reacciones» (p. 215). Las ambiguas transiciones de un yo-narrador a otro refuerza el retrato colectivo. A veces no es Paco quien narra, sino un profesor bastante mayor que había participado en la invasión de Cayo Confites, en 1949, sugiriendo que el letargo se extiende a algunos viejos miembros de la oposición. La confusión sobre quién narra el texto es evidente en el pasaje siguiente: «Y alguien (Paco o no Paco, Persio o no Persio), alguien, cualquiera, el que narra o no narra)» (p. 75).

La significación de De abril no se limita al retrato colectivo de los años postrujullistas. En otro nivel, Veloz se aleja del pasado reciente y explora un patrón binario de opresión-rebelión como arquetipo de la historia dominicana. La visión unitaria dictador/dictadura contribuye a estructurar esta significación, pero de igual importancia son tres breves

${ }^{23}$ Aunque no se publicó hasta el año 1975, Veloz terminó la novela en 1970. Véase Doris Sommer, One Master for Another (Lanham, New York/London: University Press of America, 1983), p. 197. 
relatos que el autor incorpora inicialmente en el segundo capítulo, sin ninguna transición introductoria. El primero, titulado $« 28$ de abril de 1965 », enlaza con la época postrujillista y describe el esfuerzo heroico de unos tuberculosos de luchar contra las tropas norteamericanas, llamadas a reprimir una insurrección popular que exigía la restauración del gobierno de Bosch. Los otros dos relatos son sacados de la historia dominicana más antigua: «28 de abril de 1865 » presenta el intento de unos campesinos de oponerse a los españoles durante la guerra de la restauración, y «el 28 de abril de 1605», la rebelión de Hernando Montoro contra las órdenes de despoblar el norte de la isla ${ }^{24}$. La repetida narración abrupta de los tres sucesos debilita el propósito de recrear una época determinada, porque desmantela la cronología ${ }^{25}$. Además, como destaca Doris Sommer, es posible concebir el arquetipo como una forma antihistórica, porque su estructura estática niega los cambios que marcan los diferentes períodos de la historia ${ }^{26}$. Sin embargo, y paradójicamente, son precisamente los sucesos paralelos de distintas épocas los que logran introducir en el texto alguna esperanza de cambio. Con cada uno de los tres episodios el autor retorna a los orígenes revolucionarios de la sociedad dominicana, «a ese momento del pueblo en armas que se reconoce a sí mismo como protagonista de la historia» ${ }^{27}$. Los sucesos no forman un arquetipo triunfal, pero sí subrayan un latente espíritu libertador.

El valor relativo del hecho y del arquetipo es un tema predilecto de los personajes, y sus discusiones contribuyen a la autorreflexión de la novela. Así, al confundir el narrador al coronel Aguirre con el coronel Paz, por ejemplo, hace que los personajes discutan la validez de alterar los datos biográficos incorporados en una novela. Las dos versiones acerca de la muerte de Aguirre - -se suicida después de pasar una temporada «neutralizado» en una finca de café, o ya convertido en izquierdista, se

${ }^{24}$ Frank Moya Pons, Colecciones dominicanas. Historia dominicana (Santiago, R. D.: Universidad Católica Madre y Maestra, 1982), p. 55, describe la rebelión que encabeza Montoro de la manera siguiente: «Esta fue una verdadera rebelión popular de la gente común, mulatos y negros libres que veían en las despoblaciones el comienzo de su ruina, y aunque todavía al año siguiente Montoro y su grupo no habían podido ser capturados, ni lo serían nunca, las persecuciones arrojaron más de setenta personas ahorcadas "por haber tratado y comunicado con enemigos después de la nueva ley".»

${ }^{25}$ Genette (pp. 115-116) define la narración repetitiva (repeating narrative) de la manera siguiente: «Narrating $n$ times what happened once.»

${ }^{26}$ Doris Sommer, «Good-Bye to Revolution and the Rest: Aspect of Dominican Narrative Since 1956», en The Latin American Literary Review, vol. VIII, núm. 6 (primavera-verano 1980), p. 226.

${ }^{27}$ Rama, p. 22. 
muere en un complot - anima la discusión. Uno de los personajes opina que la versión de izquierdista quitaría valor arquetípico al personaje y que tal vez sería mejor cambiar los hechos. Otro propone la alternativa de combinar las características del coronel Paz con las de Aguirre para dar con un «típico militar de la dictadura» (p. 159). El protagonista responde que crear figuras compuestas es una señal de miedo a la realidad (p. 240).

El discurso de la novela, no las discusiones de los personajes, resuelve la pregunta ¿hechos históricos o arquetipos? Basándonos en el texto de De abril, habría que concluir que se trata de una falsa dicotomía, y que, realmente, no existe entre ellos una división tan clara como parece a primera vista. No cabe duda de que los hechos históricos abundan en esas partes del texto que recrean la época postrujillista, pero en realidad los arquetipos también provienen de la historia dominicana. La diferencia reside en que los hechos son mucho más seleccionados, debido, en parte, a la escasez de documentación, y en parte, a que abarcan un período de mayor extensión, desde la época colonial hasta el presente ${ }^{28}$. Las dos estructuras no sólo comparten una base histórica, sino que las dos rehúyen un discurso objetivo, neutral, científico, de la «no-ficción» ${ }^{29}$. Tanto la visión específica como la panorámica vienen acompañadas de «indicadores» que crean, o una reacción positiva, o una reacción negativa en el lector ${ }^{30}$. En las secciones en que predomina una acumulación de hechos históricos - la caída de Trujillo y sobre todo los años posteriores a su muerte - existe una mirada hacia el pasado inmediato que señala el abuso del poder y la desintegración de la izquierda. En cambio, los arquetipos proyectan una mirada hacia el futuro con la esperanza de que el espíritu libertador del pueblo renazca.

Visiones que vacilan entre fatalistas y triunfales dejan el texto abierto a más de una lectura. La ausencia de una última significación no disminuye el valor estético de la novela, como tampoco la falta de una estruc-

${ }^{28}$ La contraposición de los hechos históricos y los arquetipos introduce el tema de la división entre la historia y la ficción. La posición de Veloz parece reflejar la de Hayden White, «The Historical Text as Literary Fiction», en The Writing of History, ed. de Robert H. Canary (Madison: The University of Wisconsin Press, 1978), p. 53: "Historians may not like to think of their wrorks as translations of "fact" into "fiction"; but this is one of the effects of the work.»

${ }^{29}$ Para una discusión del «discurso científico» y su relación con la ficción, véase Walter Moser, «The Factual in Fiction», en Poetics Today, vol. 5, núm. 2 (1984), pp. 411-428.

3in Michael Riffaterre, Semiotics of Poetry (Bloomington: Indiana University Press, 1978), pp. 1-46, emplea el término «indicador» (marker) en su discusión de las orientaciones positivas y negativas que se crean en el texto poético. 
tura determinada. Al contrario, crean un texto en proceso de desarrollo, conforme al modelo bahktiniano de la novela, que involucra al lector como co-creador, enlazando el placer estético ${ }^{31}$. Pero tanta ambigitiedad y tanta negación de patrones introducidos parecen relegar la obra a la posición de un juego absurdo, poniendo en duda la novela como medio de enfrentarse con la situación urgente del país. Sin embargo, el mayor papel productivo del lector intensifica la experiencia del texto como acontecimiento, y, por tanto, le lleva hacia una comprensión sintética de la realidad dominicana que presenta el autor. Se vislumbran, dentro de un contexto emocional, la complejidad de la estructura del poder, la tradición de la figura patriarcal, la división de clases sociales, la intervención extranjera.

\section{«LA BIografía difusa de SOMbra CASTAÑEDA»}

Las posibilidades sintéticas del discurso literario se realizan en La biografía difusa de Sombra Castañeda, porque el autor desarrolla en pleno el subgénero, presentando al dictador y al pueblo y su interrelación. El protagonista, Sombra Castañeda, tiene como meta el poder absoluto. Su reacción a las dificultades que enfrenta, su eventual soledad, su desintegración final y su deseo de destruir a todos los que le traicionan representan una personalidad tiránica ${ }^{32}$. Varios personajes que pertenecen a sectores sin poder político ni económico - los indios, los negros y los obreros- expresan la situación de los oprimidos. Otra característica que se asoma, con cierto recelo, en De abril, el encontrar patrones arquetípicos en la historia dominicana, se convierte en una preocupación central en La biografía. La mirada no sólo vuelve hacia los intentos de liberación, sino también hacia los actos de opresión, reforzando la visión sintética. También se extienden los límites de la autorreflexión de un interés en la escritura literaria, a la inquietud por el lenguaje como vehículo cultural, sobre todo con respecto a la formación y prolongación de la dictadura, y se multiplica sustancialmente el número de distintos discursos que entran en el diálogo textual. Pero la mayor innovación, tanto en la novelística de Veloz como en el subgénero, es la elaboración de una estructura alegórica ${ }^{33}$.

${ }^{31}$ M. M. Bakhtin, «Epic and Novel», en The Dialogic Imagination, editado por Michael Holquist (Austin and London: University of Texas Press, 1981), pp. 3-13.

${ }^{32}$ La reacción desesperada frente a la traición, la longevidad fantástica y el fin solitario de Sombra Castañeda se conforman al patrón del dictador establecido en las novelas de los años 1970, sobre todo El otoño del patriarca.

${ }^{33}$ Brian J. Mallet, «Dictadura e identidad en la novela», en Arbor, vol. CI, 
Angus Fletcher concluye que «allegories are the natural mirrors of ideology», y su uso tradicional en los textos persuasivos y doctrinales lo confirma ${ }^{34}$. Las posibilidades ideológicas de la alegoría explica por qué es un patrón apropiado para una narrativa que siempre condena la tiranía y afirma los derechos de los oprimidos. La definición básica de la alegoría que ofreció Quintiliano - decir una cosa al querer decir otra- necesita ampliación, para diferenciar la alegoría de otras modalidades, cuya estructura también es binaria. Se puede añadir que la alegoría se extiende a lo largo de una narrativa y que entre las palabras y la significación no existe una correspondencia antitética, como en la ironía, sino paralela. El binarismo paralelo se manifiesta en dos niveles: el primero es de «ficción», explícito y concreto, y el segundo implícito, frecuentemente abstracto y de alguna manera «real». Carolyn Van Dyke resume la esencia de la alegoría de la manera siguiente: «Allegory, the narrative of universals, envisions human life as a continual interchange between temporal events and eternal pattern» ${ }^{35}$.

En La biografía, el nivel explícito es un mundo fantástico de figuras arquetípicas, de espíritus muertos y de dioses que se relacionan con la gente de un pueblo llamado Barrero, situado al pie de la sierra Martín García. Sombra Castañeda, de ascendencia española, ya tiene siglos de vida al comenzar la primera narración. Habita las alturas de la sierra, proyectando una sombra de tiranía sobre el lugar. A los siete años de edad

núms. 393-394 (septiembre-octubre 1978), pp. 59-73, destaca la alegoría en El secuestro del general (Aguilera Malta, 1973), pero yo entiendo la alegórica animalización y mecanización de los personajes como parte de la visión satírica/irónica del texto, no su estructura principal.

${ }^{34}$ Angus Fletcher, Allegory. The Theory of a Symbolic Mode (Ithaca: Cornell University Press, 1964), p. 368. Edwin Honig, Dark Conceit. The Making of Allegory (London: Faber and Faber, 1959), p. 4, destaca que el aspecto doctrinal de la alegoría -elaborada en la retórica clásica para discusiones persuasivas y en la tradición medieval - llevó a considerarla demasiado explícita y por eso inferior al simbolismo. En una reevaluación reciente de la alegoría, Carolyn Van Dyke, The Fiction of Truth. Structures of Meaning in Narrative and Dramatic Allegory (Ithaca: Cornell University Press, 1985), pone énfasis en que la «inferioridad" de la alegoría se debe a una lectura errada que impide experimentar la complejidad de la forma: «To read an allegory properly is neither to extract a moral nor to construct a geometry of its referents but to follow what Roland Barthes calls "the every movement of meaning". In allegory that movement is particularly complicated. The text operates on what may be called a vertical and horizontal axis, and the two continually intersect: as the narrative progresses, its agents appear in various forms and at various levels of abstraction, and the means by which they are signified affects and even constitutes the narrative» (pp. 45-46).

${ }^{35}$ Van Dyke, p. 63. 
se le borró el ombligo, señal de un destino fuera de lo común. Fue cien años después del primer gobierno de Santana cuando decidió establecer su propia dictadura. Como un «agente endemoniado», en un sentido mágico-religioso, Castañeda está poseído por una sola idea: conseguir el poder total ${ }^{36}$. La variedad de sus acciones está severamente limitada, porque siempre actúa a base de la obsesión de superar las dictaduras previas de Santana, Lilís y Báez. Sombra viene del pasado, pero su meta es controlar el futuro.

En la alegoría, la obsesión de la figura central determina las acciones de varios personajes secundarios. Los principales colaboradores de Sombra Castañeda tienen poderes extraordinarios, que podrán ayudarle a realizar el plan de dominación. Por ejemplo, Antonio el bacá, que sólo empezó a vivir como espíritu cuando se murió, en 1825, es un ser encarnado en animales y capaz de transformarse rápidamente de una forma en otra. Miguel, un indio protegido por los dioses de las aguas, va acompañado de un puerco y de una perra de tetas blandas que conoció en 1515. Hijo de un cacique, fue con su madre a La Vega cuando los blancos ponían a trabajar al indio y luego huyó a la sierra con otros. Curibamgó es un negro bembú que vive convertido en agua en el arroyo Mordán, cerca de donde castraban a negros en 1650, y Mimilo es el brujo de Barrero con el poder de curar. Como es evidente de las descripciones de estos personajes, existe en el texto una serie de referencias históricas que forman un arquetipo de la opresión y del frustrado intento de los indios y de los negros de liberarse desde la época colonial.

La historia de Sombra Castañeda y sus aliados se conforma al patrón lineal de una búsqueda, creando un movimiento horizontal determinado por la obsesión del «agente». Hay un progreso inicial hacia la meta de dominación, pero luego el tirano se enfrenta con «batallas» de oposición. El libro está dividido en tres «Movimientos». En el primero se expone el proyecto, asignando papeles específicos a cada colaborador, y empieza la implementación que lleva a confrontaciones con la gente de Barrero, y con Serapio Rendón, una figura que articula los derechos de los oprimidos y su poder libertador. Rendón hereda «la necesidad de abrir brechas y romper las cerrazones» (BD, p. 110) de su abuelo, quien luchó contra la tiranía y sintió "como su propia sangre la matanza de los haitianos» (BD, p. 117). El sombrero de Serapio, igual que el de Liborio, víctima de la primera ocupación norteamericana, simboliza su fe en el pueblo. A pesar de la presencia de Rendón, se sigue con la implementación del plan. Antonio el bacá y el indio Miguel emprenden viajes para conse-

${ }^{36}$ Fletcher, pp. 40-41. 
guir la ayuda de los espíritus y de los dioses que tienen la capacidad de controlar la naturaleza. En el segundo «Movimiento» se perfila el fracaso eminente del tirano, y en el tercero, éste, literalmente, se disuelve pedazo a pedazo: «Sombra Castañeda, detrás del caobo, miraba con delirio y enorme temor cómo se deshacían ahora sus piernas, sus zapatos de general de brigada, los botones de un magnífico uniforme y las dos condecoraciones hechas con trino de ruiseñor» (BD, p. 204).

Lo que da coherencia al movimiento horizontal no es tanto una metonimia de causación como una que proviene de los patrones de la magia y los rituales arraigados en la alegoría. Son frecuentes el desdoblamiento, las repeticiones y la simetría. Los capítulos y las secciones que no forman parte de la trama lineal reflejan estas estructuras repetitivas: hay tres capítulos (VI, IX, XVIII) que presentan sueños de Serapio Rendón; cuatro (VII, IX, XIII, XV) que satirizan un juicio contra Rendón, y dos (XVI, XIX) en los cuales Castañeda se describe a sí mismo enfrentándose con el fracaso del plan de dominación. Además, hay seis secciones tituladas «Escolapio Ramírez» esparcidas por la novela, y otras doce de «Música de fondo», que reiteran, en forma de letanía, la retórica de la radio oficial.

Las raíces mágico-rituales de la alegoría se unen al del mundo concreto en que se mueve Sombra: un mundo saturado de las creencias taínas y afro-haitianas. Esta unión proyecta una de las significaciones más importantes del libro: el rescatar del silencio elementos fundamentales de la cultura dominicana. Las divinidades, el animismo, la mitología, los ritos y los médico-hechiceros que se describen en la novela remontan a estas dos culturas. Por ejemplo, Guabancex, Guatauba, Coatrisquié, Boinayel y su heraldo Maroya, dioses relacionados con las aguas, las lluvias y las inundaciones, son identificables como dioses tainos ${ }^{37}$. Otras figuras, como los galipotes, los bacás, los gagás y los petrós, tienen origen haitiano. Otro aspecto de las creencias taínas incorporado en la obra es el animismo de los espíritus de los muertos, las llamadas opias, a quienes se podrían identificar, como a Sombra Catañeda, por la ausencia del ombligo. Igualmente, las ceremonias que encabeza el médico-hechicero Mimilo tienen afinidades tanto con los ritos de los indios como con los de los haitianos. Los taínos se preparaban para los rituales intoxicándose, y Mimilo hace lo mismo bebiendo clerén y taifá, que, junto con el ritmo de los tambores, lo transportan a un estado de encantamiento ${ }^{38}$.

${ }^{37}$ Roberto Cassa, Los tainos de la española (Santo Domingo: Universidad Autónoma de Santo Domingo, 1974), pp. 153-173.

${ }^{38}$ Irving Rouse, «The West Indies: An Introduction», en Handbook of South 
A1 incorporar en la novela sucesos encubiertos por la historia oficial -crímenes raciales y ritos olvidados-Veloz desconstruye el mito de un lenguaje único. La novela se abre a la polifonía, y el lector oye algunos de los distintos lenguajes de la isla. No se trata solamente de palabras y estructuras diferentes, sino que, como subraya Bahktin, cada lenguaje trae consigo un contexto, sobre todo social e ideológico ${ }^{39}$. Al incluir la diversidad socio-linguiística del país, Veloz empieza a remediar el defecto de la narrativa dominicana que percibe Manuel Rueda: la falta del «gran encuentro del novelista criollo con sus palpitantes materiales humanos y lingüísticos» ${ }^{40}$.

La descripción inicial del indio Miguel introduce el tema de la diversidad de idiomas en la novela: «Sabía Miguel más que el castellano, la lengua de los indios y la de los negros de Manieles. De modo que cuando nos encontramos no podía yo entenderme con él» (BD, p. 17). Al intervenir personajes como Remigio el gagá, el alcalde de un pueblo cercano a Barrero, o Curibamgó o Mimilo, el autor transcribe su forma de hablar. Por ejemplo, Mimilo se expresa de la manera siguiente: «-Jum. Yo quié decí que la combina tá echa. Pronto tó va ja cambiá. La mata se irán pal sitio que deban tá. La sagua, lo río, van a mejorá la tierra. Ya se jabló» (BD, p. 46). La inclusión de algunos merengues, como «Siña Juanica, de poi Dio», que canta del temor de una madre de perder a su niño por falta de medicinas (BD, p. 132), es otra fuente del lenguaje popular. Numerosos dominicanismos aparecen en las descripciones de la flora del campo («yagrumos», «cocuyos», «caimoní», «ahuyama») y para nombrar algunos animales y aspectos de la casa. La poliglosia de la novela queda resumida en el vocablo «palma», cuya significación es mucho más compleja para el campesino pobre que para la clase alta de la capital o para el hispanohablante de algún otro país: «Se encontró con que la palma era la madera más importante y vital: sus hojas servían como techumbre, su tronco como

American Indians, ed. de Julian H. Stewart, vol. 4 (New York: Cooper Square Publishers, 1963), pp. 534-538.

${ }^{39}$ M. M. Bakhtin, "Discourse in the Novel», en The Dialogic, explica la heteroglosia del lenguaje: «Thus at any given moment of its historical existence, language is heteroglot from top to bottom: it represents the co-existence of socio-ideological contradictions between the present and the past, between differing epochs of the past, between different socio-ideological groups in the present, between tendencies, schools, circles and so forth, all given a bodily form» (p. 291), y luego subraya cómo el novelista puede entretejer «los lenguajes» para lograr expresar sus intenciones y valores: "They may all be drawn in by the novelist for the orchestration of his themes and for the refracted (indirect) expression of his intentions and values» (p. 292).

40 Rueda, p. 119. 
poste para las viviendas, su madera como tabla rasurada para las casas, su corazón como palmito para las pailas colectivas, su fronda como lugar de descanso y sortilegio» (BD, p. 61).

La heteroglosia de la realidad retratada no se limita a la distinción entre los campesinos y los urbanos o entre las clases alta y baja. Otros factores relacionados, como la educación, la profesión, la etnicidad, contribuyen a la formación de diferentes «lenguajes». Por ejemplo, el novelista aprovecha el juicio en contra de Rendón para satirizar el lenguaje jurídico-legal y el nivel relativo de educación de dos personajes. El mecanógrafo anota los comentarios siguientes con respecto a la manera de hablar de Mimilo: «El señor Mimilo no habla muy bien y tengo que poner de mi parte para que ete interogatorio quesde bien hescho como dio nuestro señol manda» (BD, p. 147). El texto incluye también un lenguaje fronterizo, en el cual el francés-haitiano juega un papel significativo y otro retórico, que proviene de la transcripción de documentos coloniales que describen la persecución de esclavos alzados o de la recreación de los elogios oficiales de Trujillo. El autor intensifica la poliglosia de la obra aún más al mezclar distintos estilos literarios, incluyendo pasajes líricos, de tono elevado y culto, y otros surrealistas.

La intersección de tantos «lenguajes» desemboca en la autorreflexión, y la palabra, dentro y fuera del texto literario, se convierte en una de las preocupaciones principales del autor. El poder político de la palabra recibe un énfasis especial a través de la narración del plan de dominación. Por ejemplo, lo primero que hace Sombra, al establecer su dominio, es escribir un decreto y reunir a sus colaboradores para que lo firmen. (BD, p. 26). Los marginados también comprenden que la palabra es el eje del poder. Para Serapio Rendón, el primer paso hacia la liberación es luchar contra los discursos gastados y el elogio desmesurado, y el último, la creación de un lenguaje nuevo. Por eso declara la «guerra florida contra el diccionario agotado de toda dictadura» (BD, p. 186). El silencio final del tirano señala la desintegración de su poder: «Sombra Castañeda quiso decir unas palabras de despedida, pero su lengua se había vuelto niebla y el sonido de su voz se convertía en neblina azul que flotaba, como un pañuelo, sobre las piedras redondas del arroyo Mordán» (BD, p. 208). Es la voz de las vecinas de Barrero y el eco de los abuelos, que resuenan al final de la novela. Al dejar la palabra en boca del pueblo, Veloz sugiere un cambio en la estructura del poder y el comienzo de una época democrática.

La orquestación de diversos lenguajes en La biografía difusa de Sombra Castañeda tiene, aparte de su aportación socio-ideológica, dos resultados: exige la participación del lector y hace que el texto sea autorre- 
flexivo. Estas dos características reflejan la estructura principal de la novela. Los estudios actuales de la alegoría destacan precisamente el papel preeminente del lector, y con ello un alto grado de autorreflexión y un enfoque en la naturaleza del lenguaje ${ }^{41}$. La historia del plan fracasado de Sombra Castañeda establece el movimiento horizontal de la estructura alegórica, pero el movimiento vertical requiere la creatividad del lector. El texto reta al lector a descubrir el nivel implícito que corresponde al mundo fantástico de Sombra Castañeda. Una segunda trama introduce lo que parece ser la explicación del nivel explícito. El protagonista de la trama secundaria es Esculapio Ramírez, un personaje verosímil de clase baja, quien se opone al régimen de Trujillo. Esculapio agoniza en un hospital, donde falta todo lo necesario, oxígeno, plasma, compresas. Nació en el barrio de Villa Francisca, y ha sido juzgado y torturado varias veces por sus actividades contra el gobierno. Pronto se establece una correspondencia entre Sombra Castañeda y Trujillo y otra entre Serapio Rendón y Esculapio Ramírez. Gradualmente, el autor une las dos historias. Con la presencia del militar Beltrán en Barrero, la enorme separación entre el mundo fantástico y el otro real se reduce a una cuestión de geografía: la ciudad es el centro del gobierno de Trujillo, y el pueblo de Barrero y el campo alrededor, el dominio de Castañeda. La confusión entre Rendón y Ramírez funde aún más los niveles alegóricos. El mismo día en que Rendón llega a Barrero, Mimilo expresa dudas sobre su verdadera identidad: "Ya me han dicho que viene huyendo... que no se llama Serapio Rendón, sino Esculapio Ramírez» (BD, p. 73). La violencia es otro elemento que une las dos historias. Sombra inició su absolutismo «fusilando lagartijas» y lo terminó matando a sus enemigos (BD, p. 175), y los militares trujillistas castraban a prisioneros políticos y fusilaban a niños por equivocación (BD, pp. 42, 164). La coincidencia de la desintegración de Sombra Castañeda con la muerte de Trujillo y la desaparición de Serapio Rondón con la muerte de Esculapio Ramírez es otra manera de convencer al lector de que ha descubierto el nivel implícito de la alegoría.

Se entrelazan de tal forma las dos historias, que la impresión inicial de que el relato verosímil de Esculapio explica el nivel implícito de la alegoría queda desconstruida, rechazada por ser sólo un juego en el cual

${ }^{41}$ Maureen Quilligan, The Language of Allegory. Defining the Genre (Ithaca and London: Cornell University Press, 1979), p. 24, por ejemplo, resume estos conceptos diciendo: "That the final focus of any allegory is its reader, and that the real "action" of any allegory is the reader's learning to read the text properly... Because allegory is (and always has been) the most self-reflexive and critically self-conscious of narrative genres, and because its purpose is always to make its reader correspondingly self-conscious, the reader necessarily belongs in its descriptions.» 
el autor enreda deliberadamente al lector. El relato Trujillo-Ramírez no forma un segundo nivel, sino que encaja perfectamente dentro de los arquetipos del mundo fantástico de Sombra Castañeda: «Arriba y abajo era igual; arriba, la tiranía; abajo, la dictadura» (BD, p. 84). El primer movimiento vertical no desemboca en la significación de la obra. Ya no es posible ver en el fin optimista del nivel explícito - la desintegración de Sombra y la palabra en boca del pueblo- el fin del abuso del poder en la República Dominicana. Una lectura retroactiva confirma que es el lector quien tiene que crear las sendas del movimiento vertical para llegar a la verdad del texto. Como posibles componentes del nivel abstracto y, al mismo tiempo, real de la alegoría podrian fịurar la condenación de la opresión y la criminalidad de las dictaduras, y el reconocimiento de un patrón histórico de represión en la República Dominicana que ha afectado, sobre todo, a los indios y a los negros. Otros componentes que Veloz no incluye en novelas anteriores son, la riqueza linguiística-cultural tradicionalmente olvidada en la literatura, el papel clave de la palabra - tanto en la literatura como en la política-, la esperanza de un nuevo lenguaje de la liberación, la alegría de que, por fin, se disuelve la figura del dictador y la tristeza de que la liberación llegue demasiado tarde para muchos. La significación que cada lector encuentra en la novela se enlaza con el futuro del país, un futuro que queda sin delinearse, como un reto.

\section{Conclusiones}

Las cuatro novelas de Marcio Veloz Maggiolo examinadas aquí reflejan características típicas de la narrativa de dictador/dictadura de la República Dominicana: el régimen de Trujillo, como base real de la ficción, y un enfoque en los efectos de la dictadura - sobre todo la implantación de la violencia como único medio de interacción social- más que en la personalidad del tirano. La trayectoria de las obras de Veloz es similar a las etapas de la evolución del subgénero. En El prófugo, como en las primeras narrativas de dictador/dictadura, predomina el mensaje: una emocionada y estridente condenación de la opresión dictatorial. La ausencia de la figura del dictador impide una visión sintética de la estructura del poder, y la escasez de patrones que exigen la participación del lector reduce el placer de la lectura. Con Los ángeles de hueso Veloz se mueve como un malabarista, logrando el balance delicado entre el deleite y la enseñanza. La intertextualidad del espacio cerrado y de los leitmotivs permiten al autor explorar la psicología de un individuo que intenta sobrevivir la represión violenta del gobierno, una perspectiva innovadora den- 
tro del subgénero. Esta obra confirma que una novela «de dictadura» puede alcanzar un alto nivel estético.

En De abril en adelante, Veloz ensaya la integración de los dos aspectos del subgénero. Sigue predominando el efecto de la represión -el trauma prolongado de los intelectuales en los años postrujillistas-, pero la figura del coronel Aguirre añade una visión del poder desde adentro, extendiendo los límites sincrónicos del estudio del poder. La extensión diacrónica también se alarga en esta obra, porque los arquetipos llevan la mirada del lector hacia atrás, hasta la época colonial, y el uso de la ambigüedad la proyecta hacia un futuro indefinido. La biografía difusa de Sombra Castañeda es la culminación de la narrativa de dictador/dictadura velociana y representa la realización en pleno de las posibilidades del subgénero. Tanto la alegoría —una contribución original al desarrollo de la narrativa de dictador/dictadura- como la poliglosia co-optan al lector como co-creador, colocándolo en una posición dialógica con el texto como obra literaria y con la realidad dominicana. 